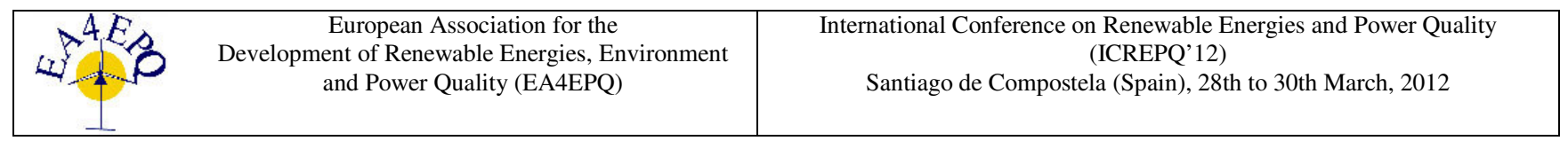

\title{
Permanent magnet wind generators: control strategies to manage voltage unbalances
}

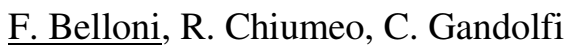 \\ RSE - Ricerca sul Sistema Energetico \\ via Raffaele Rubattino, 54, 20134, Milano (Italy) \\ Phone number::+390239921, \\ e-mail: federicoriccardo.belloni@rse-web.it, riccardo.chiumeo@rse-web.it, chiara.gandolfi@rse-web.it
}

\begin{abstract}
The paper presents four different control strategies for grid connected voltage source inverters, devoted to the interface of permanent magnet synchronous wind generators with the distribution network. A common dq-axes control is compared with two modified controls in the dq frame which take into account also negative sequence components of voltages, and currents and a control approach in the stationary $\alpha \beta$ frame which reduces the computational complexity of the control itself. An ATPDraw model of a $2 \mathrm{MW}$ wind generator has been developed and employed for simulating the responses of the four control schemes to voltage unbalances and voltage dips. The improved control strategies have shown better performances in terms of reduction of $100 \mathrm{~Hz}$ oscillating power components during network voltage unbalances.
\end{abstract}

\section{Key words}

Permanent Magnet Wind Generators, Voltage Source Inverters, Control Strategies, Network Voltage Unbalances.

\section{Introduction}

During the last years, there has been a large increase of the installed wind capacity in Europe and worldwide. Recently, the predominant trend for medium power wind turbines (up to $2 \mathrm{MVA}$ ) consists in using synchronous generators instead of Doubly Fed Induction Generators (DFIGs), more often employed in the past [1, 2]. Nowadays power electronics converters are used for connecting the generators to the distribution grid, in order to regulate the frequency and the power factor of the currents injected into the network.

The large installed wind capacity makes desirable that wind generators remain connected to the grid in case of network disturbances, unbalances or faults. For this reason, a suited design of the power electronic converters and special control strategies must be considered [2].

This paper describes the model of a 2 MVA Permanent Magnet Synchronous Wind Generator (PMSG) connected to a Medium Voltage $(20 \mathrm{kV})$ distribution network through a three phase voltage source inverter
(VSI) and a LV/MV transformer. Special control strategies of the inverter, devoted to the management of grid voltage unbalances, are described. During grid unbalances, the power injected by the wind generator into the network is affected by oscillating components with double frequency in respect to grid frequency. Such components are undesired since they downgrade the power quality and can affect other systems connected to the distribution network.

Digital simulations performed in ATPDraw compare the distributed generation system behaviour in case of a classical current control, in the dq-axes frame, with those obtained in presence of other control strategies used to mitigate the oscillating components of the power injected into an unbalanced network.

\section{Wind generation system}

The schematic model of the wind generation system considered in the paper is reported in Figure 1. The system is composed by:

- a wind turbine;

- a Permanent Magnet Synchronous Generator;

- a diode bridge rectifier;

- a current controlled DC-DC boost converter;

- a three phase Voltage Source Inverter;

- a LV/MV transformer.

The diode bridge rectifier generates an unregulated DC voltage from the AC outputs of the PMSG which supplies the boost converter. This latter is controlled with a hysteresis band modulation [3] and sets the current extracted from the generator. The DC-DC converter output voltage is the DC input of the VSI which regulates the voltage across the capacitor by controlling the power injected into the distribution network through the LV/MV transformer. Maximum Power Point Tracking (MPPT) algorithms are not included in the control scheme, since they involve mechanical transients and their dynamics are usually slower than those of electrical phenomena [4]. A simulation model of a $2 \mathrm{MW}$ PMSG for wind power application was developed within the ATPDraw 
environment. Table I summarizes the wind generation system design parameters.
The model was used to perform a simulative comparison among different control strategies of the VSI to optimize the inverter behaviour during network unbalances.

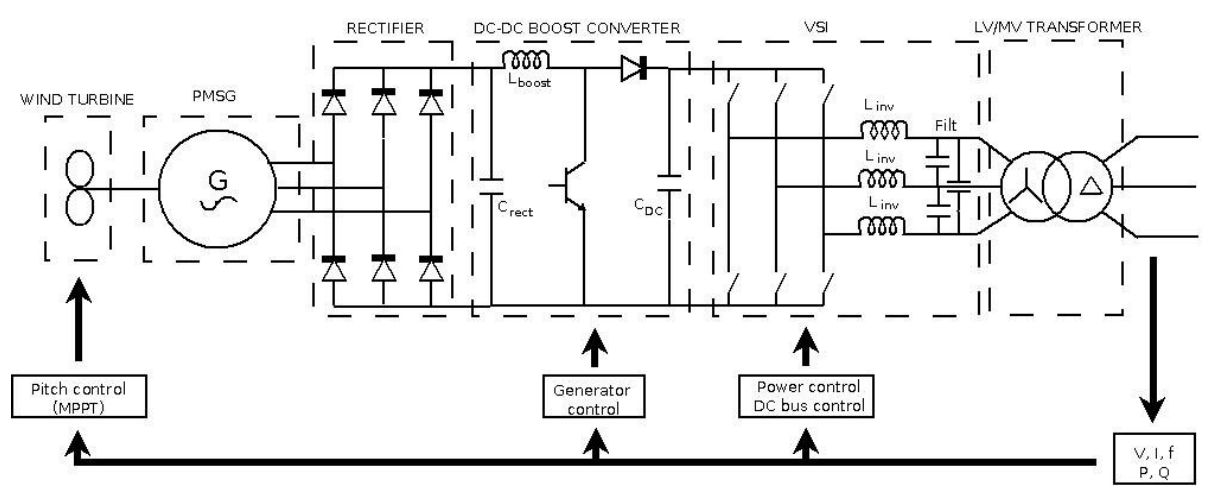

Fig. 1. Schematic model of a wind synchronous generator.

Table I. - Wind generation system design specifications

\begin{tabular}{|c|c|}
\hline \multicolumn{2}{|l|}{ Rectifier } \\
\hline $\mathrm{C}_{\text {rect }}$ & $100 \mathrm{mF}$ \\
\hline \multicolumn{2}{|l|}{ DC-DC boost converter } \\
\hline$f_{s w}$ & $15 \mathrm{kHz}$ \\
\hline $\mathrm{I}_{\mathrm{MPPT}}$ & $3750 \mathrm{~A}$ \\
\hline$\Delta \mathrm{I}$ & $\pm 100 \mathrm{~A}\left(\cong \pm 2,5 \% \mathrm{I}_{\mathrm{MPPT}}\right)$ \\
\hline $\mathrm{L}_{\text {boost }}$ & $0,18 \mathrm{mH}$ \\
\hline \multicolumn{2}{|l|}{ Voltage source inverter } \\
\hline Rated power & $2 \mathrm{MVA}$ \\
\hline $\mathrm{V}_{\mathrm{DCn}}$ & $1100 \mathrm{~V}$ \\
\hline $\mathrm{V}_{\mathrm{ACn}}$ & $220 \mathrm{~V}$ \\
\hline $\mathrm{C}_{\mathrm{DC}}$ & $100 \mathrm{mF}$ \\
\hline $\mathrm{L}_{\text {inv }}$ & $7,7 \mu \mathrm{H}(0,1 \mathrm{pu})$ \\
\hline $\mathrm{f}_{\mathrm{sw}}$ & $2 \mathrm{kHz}$ \\
\hline \multicolumn{2}{|l|}{ LV/MV transformer } \\
\hline Rated power & $3 \mathrm{MVA}$ \\
\hline LV voltage & $220 \mathrm{~V}$ \\
\hline MV voltage & $20 \mathrm{kV}$ \\
\hline Windings Connection & Dyn11 \\
\hline Series inductance $\left(\mathrm{X}_{\mathrm{cc}}\right)$ & $3,5 \mu \mathrm{H}(0,07 \mathrm{pu})$ \\
\hline
\end{tabular}

\section{Control strategies for the VSI}

\section{A. Generic current control on dq-axes}

This control approach, whose block scheme representation is shown in Figure 2, is often adopted in other type of distributed generators which require power electronics as interface with the distribution network $[3,5]$.

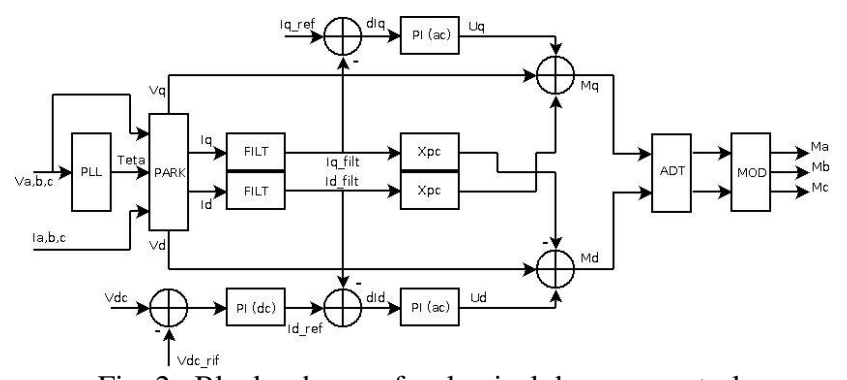

Fig. 2. Block scheme of a classical dq-axes control.
In this control scheme, the DC voltage of the VSI is compared with a reference value and the error signal is processed by a Proportional-Integral (PI) controller for obtaining a current reference on the direct (d) axis; while the orthogonal (q) axis current reference is usually set to null value for obtaining a unitary power factor. Current references are then compared with the actual current values, whose $d$ and q components are calculated with a Phase Locked Loop (PLL) synchronized with the network voltage. The current errors are processed by two PI controllers, whose transfer functions are in the form:

$$
H_{P I}(s)=k_{p}+\frac{k_{i}}{s}
$$

where $k_{p}$ is the proportional gain and $k_{i}$ the integral gain of the controller. Regulators are followed by a decoupling stage and by a feed-forward compensation, made on the network voltages to improve the control dynamics. Finally, three modulating signals are calculated from the dq-axes voltage references and sent to a classical Pulse Width Modulator (PWM).

\section{B. Dq-axes control with negative sequences compensation}

The block scheme of the dq-axes control with negative sequences compensation is shown in Figure 3.

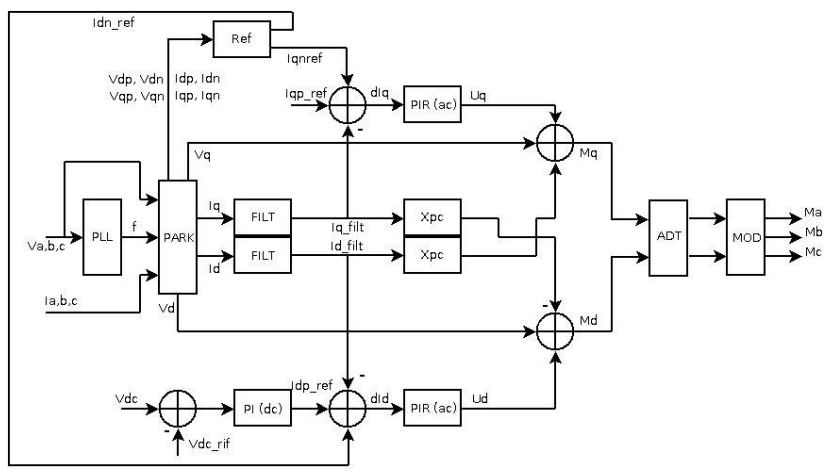

Fig. 3. Scheme of a dq-axes control with compensation of negative sequences components.

This control is similar to the previous one, with the main difference that also the currents and voltages negative sequence components, calculated on the dq-axes, are taken into account. The positive sequences components 
of each quantity ( $x_{d p}$ and $x_{q p}$, where $\mathrm{x}$ stands for current or voltage) are calculated with the usual Park transformation, while the negative ones are given by [6]:

$$
\left[\begin{array}{l}
x_{d n} \\
x_{q n}
\end{array}\right]=\left[\begin{array}{cc}
\cos (2 \pi f t) & -\sin (2 \pi f t) \\
\sin (2 \pi f t) & \cos (2 \pi f t)
\end{array}\right] \cdot\left[\begin{array}{c}
x_{\alpha} \\
x_{\beta}
\end{array}\right]
$$

where $\mathrm{f}$ is the network frequency, calculated by a PLL, and $x_{\alpha}$ and $x_{\beta}$ are the $\alpha \beta$ components of the considered quantity, calculated by the canonical $\alpha \beta \gamma$ transformation. The mean value of each quantity, given by:

$$
<x_{d, q n}(t)>=\frac{1}{t} \int_{0}^{t} x_{d, q n}(\tau) d \tau
$$

where $t$ is the current time, is then used in the control for noise filtering. Current references for negative sequence components are calculated according to the formulas [2]:

$$
\begin{aligned}
& i_{d n_{-} r e f}=\frac{1}{v_{d p}}\left(v_{d n} i_{d p}+v_{q n} i_{q p}\right) \\
& i_{q n_{-} r e f}=\frac{1}{v_{d p}}\left(v_{q n} i_{d p}-v_{d n} i_{q p}\right)
\end{aligned}
$$

Since voltage and current unbalances are represented as $2 f$ component in the dq-axes decomposition of the respective quantities, current PI regulators should be modified into Proportional-Integral-Resonant (PIR) regulators with resonant frequency equal to $2 f[2]$ :

$$
H_{P I R}(s)=k_{p}+\frac{k_{i}}{s}+k_{r} \frac{s}{s^{2}+2 \alpha s+(2 \cdot 2 \pi f)^{2}}
$$

where $k_{p}$ and $k_{i}$ have the usual meaning, $k_{r}$ is the resonant gain and $\alpha$ is a damping factor used to widen the resonant zone across $2 f$ and to maintain the controller gain finite.

\section{Second Order Generalized Integrator (SOGI) control}

The SOGI control scheme is shown in Figure 4.

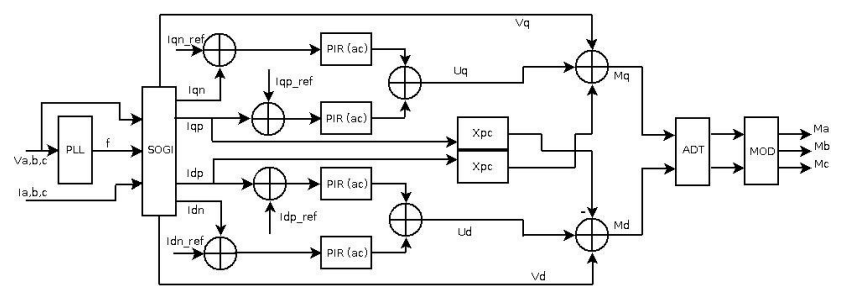

Fig. 4. Block scheme of the SOGI control.

The main difference from the dq-axes control with negative sequences compensation consists in the calculation of the positive and negative sequences of the currents and voltages dq-axes components, which are calculated starting from the $\alpha \beta$ components:

$$
\left[\begin{array}{l}
x_{\alpha} \\
x_{\beta}
\end{array}\right]=\sqrt{\frac{2}{3}}\left[\begin{array}{ccc}
1 & -1 / 2 & -1 / 2 \\
0 & \sqrt{3} / 2 & \sqrt{3} / 2
\end{array}\right]\left[\begin{array}{c}
x_{a} \\
x_{b} \\
x_{c}
\end{array}\right]
$$

Then, the SOGI filtering stage is adopted for extracting the positive and negative sequences in the $\alpha \beta$ frame [7]:

$$
\begin{aligned}
& x_{\alpha p}=\frac{1}{2} \frac{x_{\alpha} k \omega s-x_{\beta} k \omega^{2}}{s^{2}+k \omega s+\omega^{2}} \\
& x_{\alpha n}=\frac{1}{2} \frac{x_{\alpha} k \omega s+x_{\beta} k \omega^{2}}{s^{2}+k \omega s+\omega^{2}} \\
& x_{\beta p}=\frac{1}{2} \frac{x_{\alpha} k \omega^{2}+x_{\beta} k \omega s}{s^{2}+k \omega s+\omega^{2}} \\
& x_{\beta n}=\frac{1}{2} \frac{-x_{\alpha} k \omega^{2}+x_{\beta} k \omega s}{s^{2}+k \omega s+\omega^{2}}
\end{aligned}
$$

where $k=\sqrt{2}$ and $\omega=2 \pi f$ is the angular speed of the network voltage measured by the PLL.

Finally, the positive and negative components of the measured quantities are:

$$
\begin{aligned}
& {\left[\begin{array}{l}
x_{d p} \\
x_{q p}
\end{array}\right]=\left[\begin{array}{cc}
\cos (\omega t) & \sin (\omega t) \\
-\sin (\omega t) & \cos (\omega t)
\end{array}\right] \cdot\left[\begin{array}{c}
x_{\alpha p} \\
x_{\beta p}
\end{array}\right]} \\
& {\left[\begin{array}{l}
x_{d n} \\
x_{q n}
\end{array}\right]=\left[\begin{array}{cc}
\cos (-\omega t) & \sin (-\omega t) \\
-\sin (-\omega t) & \cos (-\omega t)
\end{array}\right] \cdot\left[\begin{array}{c}
x_{\alpha n} \\
x_{\beta n}
\end{array}\right]}
\end{aligned}
$$

The current components obtained by (6), (7) and (8) are then compared with the relevant reference values, calculated as in the previous control schemes, and the error processed by PIR controllers, whose outputs are summed separately on the d-axis and on the q-axis. Then the control follows the usual scheme of Figure 2.

\section{D. $\alpha \beta$-axes control}

This type of control can be used to simplify the hardware implementation of each one of the previously mentioned strategies. A schematic representation of main idea behind this control approach is represented in Figure 5.

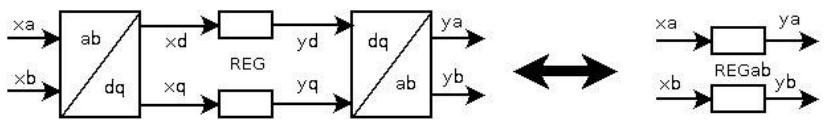

Fig. 5. Control scheme on $\alpha \beta$-axes.

Usually, the control schemes on dq-axes implies an intermediate transformation from the physical quantities to the $\alpha \beta$ frame and then from the $\alpha \beta$ frame to the $d q$ reference, a regulator for each component and then an anti-transformation stage. The control in the $\alpha \beta$ reference allows obtaining the same dynamic performances avoiding the $\alpha \beta \rightarrow$ dq and dq $\rightarrow \alpha \beta$ stages, with benefits in terms of computational complexity of the control.

Defining the control transfer function in the dq-axes frame as $H_{d q}(s)$, the equivalent control in the $\alpha \beta$ frame is given by $[6,8]$ :

$$
\begin{aligned}
H_{\alpha \beta}(s) & =\cos (\phi)\left[H_{d q}(s-j \omega)+H_{d q}(s+j \omega)\right]+ \\
& +\sin (\phi)\left[H_{d q}(s-j \omega)-H_{d q}(s+j \omega)\right]
\end{aligned}
$$

where $\phi$ is the phase delay given by $H_{d q}(s)$ at the network frequency $\omega /(2 \pi)$. For instance, for a PI controller in the form (1), since 


$$
\phi=\angle\left(H_{d q}(\omega)\right) \cong 0
$$

the controller in the $\alpha \beta$ frame takes the form:

$$
H_{\alpha \beta}(s)=2 k_{p}+2 k_{i} \frac{s}{s^{2}+\omega^{2}}
$$

The equivalence is complete under the hypothesis that the PLL instantaneously locks on the grid voltage frequency.

\section{Simulation results}

The four abovementioned control schemes were implemented into the ATPDraw model of the PMSG and simulation results were compared in two different situations:

- unbalanced network (due to the insertion of an unbalanced load);

- transient two-phase to ground grid fault.

A detailed network model was employed for simulations. The MV network is made up of a MV busbar, connected to an equivalent model of a transmission grid through a suited transformer, and five feeders represented with a distributed parameters model (Bergeron model).

The wind generator is connected at one of the feeder at 5 $\mathrm{km}$ from the MV busbar.

The unbalanced load is connected at the same feeder at 10 $\mathrm{km}$ from the busbar. It is represented as a 10 MVA load between two phases ( $a$ and $b$ ) and power factor equal to 0,9 .

Faults are simulated in another feeder at $1 \mathrm{~km}$ from the busbar.

The control, described in section 3D, represents a possible implementation of each one of the other described schemes avoiding two transformations; simulations were employed only to verify the equivalence between this approach and the one described in section 3A.

\section{A. Equivalence between the $\alpha \beta$-axes control and the $d q$ - control}

The responses of the PMSG with the inverter controlled by the two approaches (3A and 3D) in case of a network unbalance as shown in Figure 6, are reported in Figure 7. The unbalance occurs at $t=0,6 \mathrm{~s}$ due to the insertion of an unbalanced load into the network.

The amount of unbalance, in terms of ratio between negative and positive voltage on the direct axis, is $4 \%$.

The following parameters values were adopted for simulations: $k_{p}=40,72 ; k_{i}=147,06 ; \omega=2 \pi 50 \mathrm{rad} / \mathrm{s}$.

The main difference between the two behaviours is found during the settling time of the PLL, which is included in the dq-axes control only.

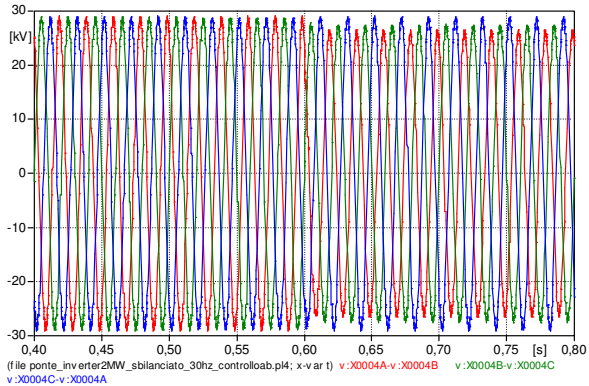

Fig. 6. Line to line grid voltages before and after network unbalance.

Instead, no significant differences are visible at the steady state, demonstrating the substantial equivalence between the two control approaches.
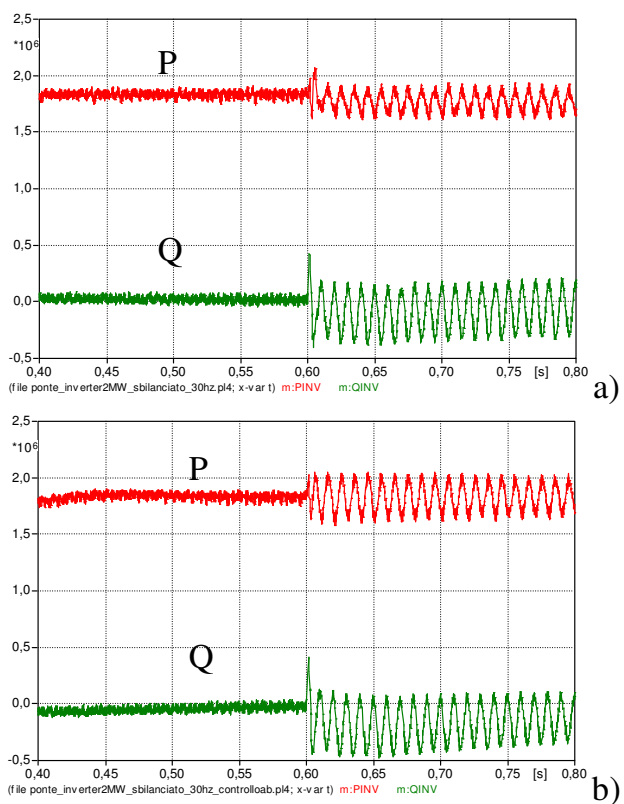

Fig. 7. Active power (red line) and reactive power (green line) at the steady state and during voltage unbalance with dq-axes control (a) and $\alpha \beta$-axes control (b).

\section{B. Responses to a network voltage unbalance}

The same network disturbance was used to compare the responses of the three control strategies in the dq frame. Figure 8 shows the active and reactive components of the power injected into the grid by the PMSG only with the controllers described in sections $3 \mathrm{~B}$ and 3C. Results should be compared with those reported in Figure $7 \mathrm{a}$. For simulations, the following values of the parameters were adopted: $k_{p}=40,72 ; \quad k_{i}=147,06 ; \quad k_{r}=10^{4} ; \quad \alpha=2 \pi$, $\omega=2 \pi 50 \mathrm{rad} / \mathrm{s}$.

A significant reduction of the oscillating components of the active and reactive power is achieved with the improved control strategies, resulting in a better power quality, even in case of network unbalances. Such a benefit is not clearly visible in the current waveforms, since the high frequency harmonics, due to switching, hide the low frequency distortion. 

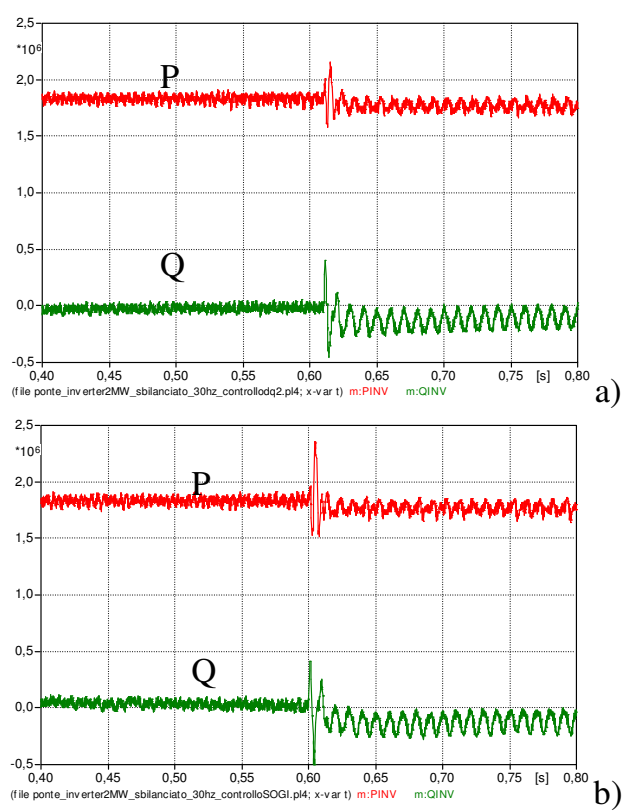

Fig. 8. Active power (red line) and reactive power (green line) at the steady state and during voltage unbalance with dq-axes control with negative sequence compensation (a) and "SOGI" control (b).

In Figure 9 the current waveforms at the MV side of the power transformer are shown.
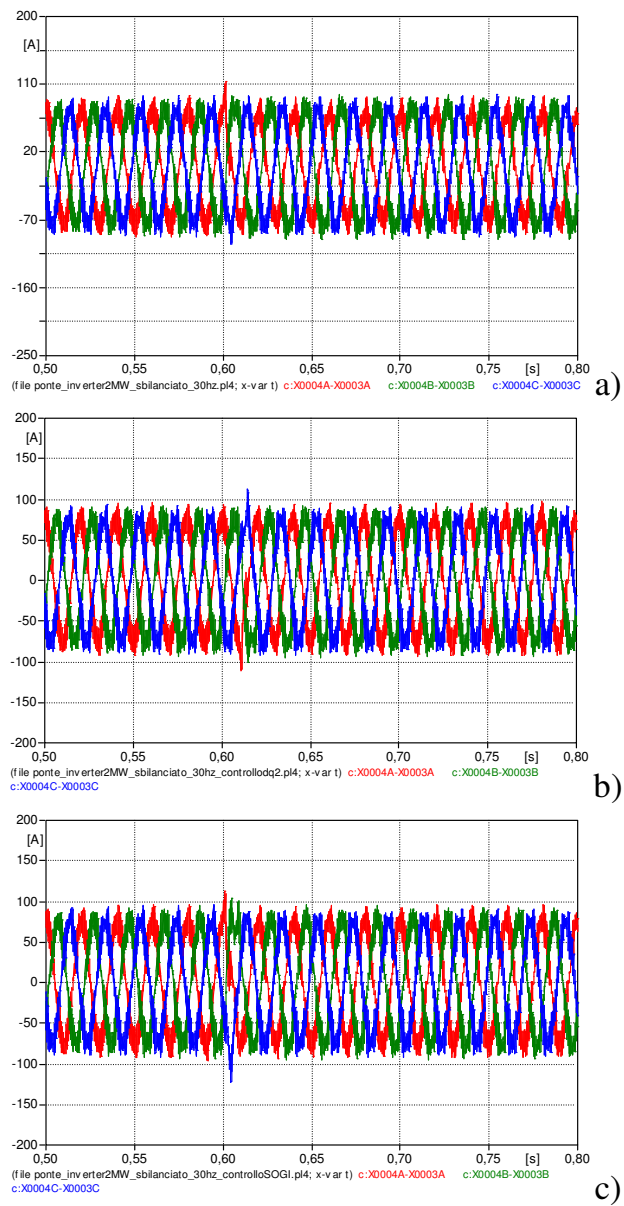

Fig. 9. Currents injected by the PMSG with usual dq-axes control (a), with compensation of the negative sequence components (b) and with "SOGI" control (c).

\section{Responses to an unbalanced voltage dip}

The responses of the three control approaches in the dqaxes frame to an unbalanced voltage dip were also simulated in order to compare their performances. The voltage disturbance is caused by a two-phase to ground fault occurring at $t=0,6 \mathrm{~s}$ and it's shown in Figure 10. The voltage dip has a residual voltage of $70 \% \mathrm{~V}_{\mathrm{n}}$ (referred to the lowest voltage) and it is cleared after $120 \mathrm{~ms}$ by the opening of the faulty line breaker, as a consequence of the tripping of the line over-current relays.

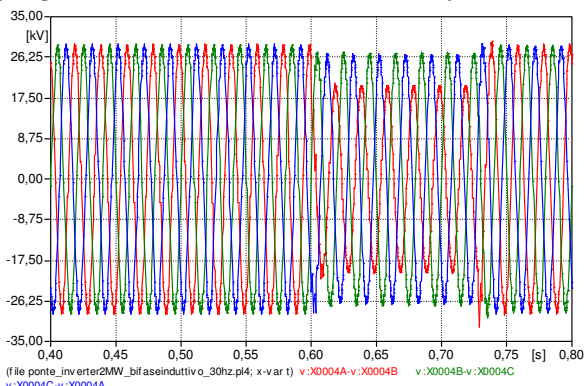

Fig. 10. Line to line grid voltage waveforms during an unbalanced voltage dip caused by a two-phase to ground fault.

The responses of the three control schemes, in terms of active power and reactive power injected into the network, are reported in Figure 11, while corresponding current waveforms at the MV side of the power transformer are reported in Figure 12.
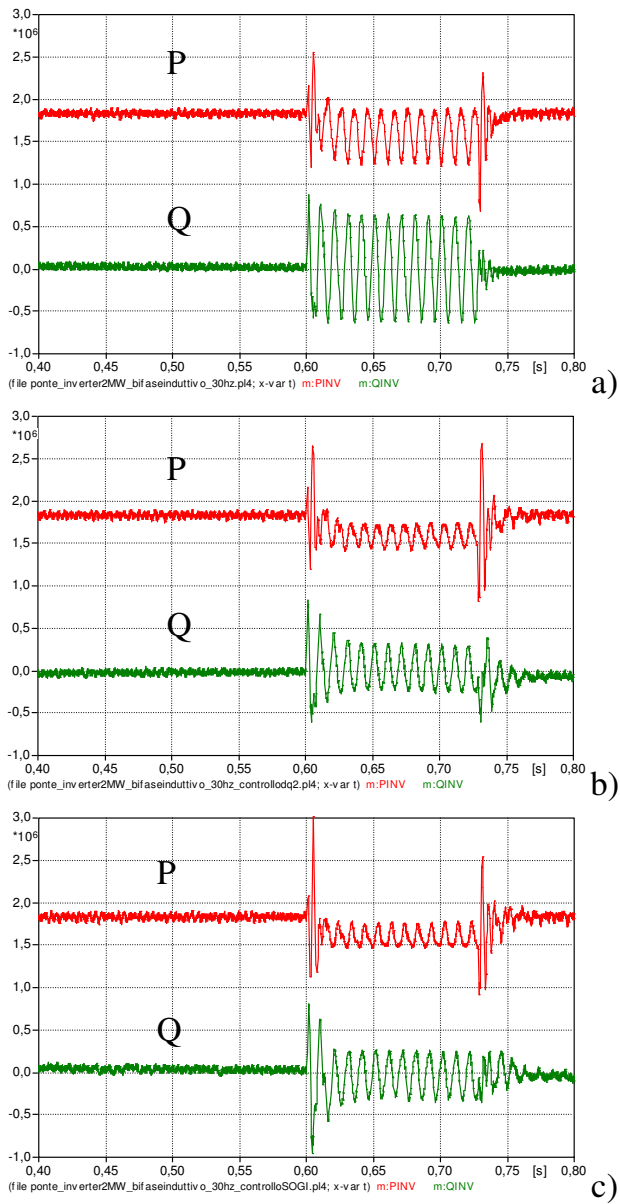

Fig. 11. Active power (red line) and reactive power (green line) injected by the PMSG with usual dq-axes control (a), with compensation of the negative sequence components (b) and with "SOGI" control (c). 


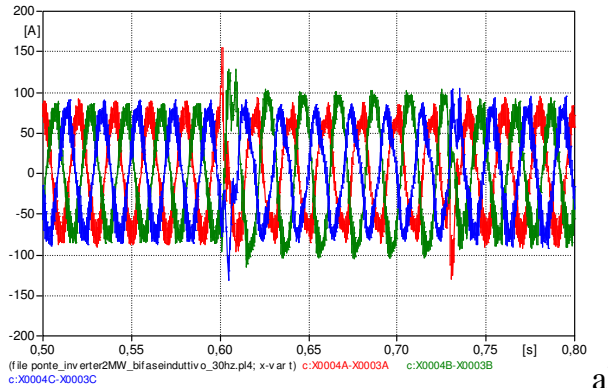

a)

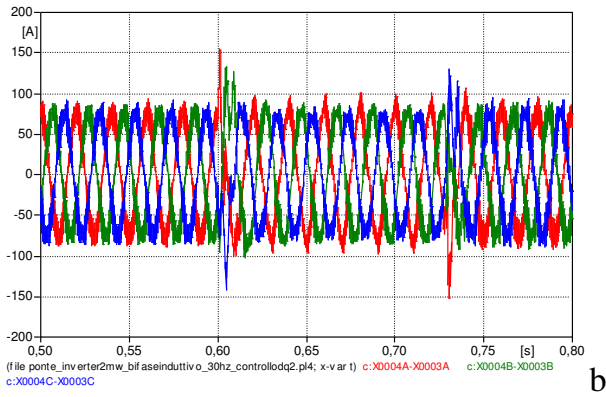

b)

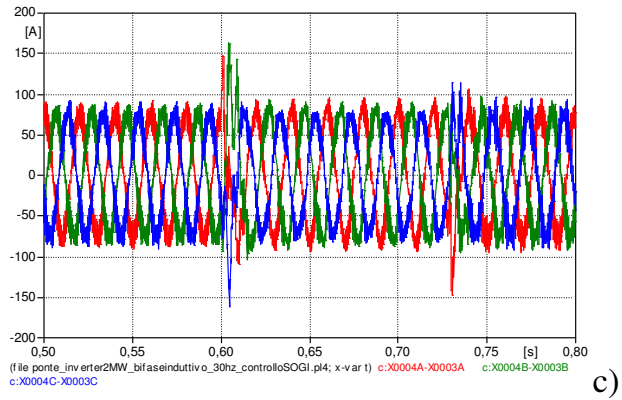

Fig. 12. Currents injected by the PMSG with usual dq-axes control (a), with compensation of the negative sequence components (b) and with "SOGI" control (c) during an unbalanced voltage dip.

A significant reduction of the $100 \mathrm{~Hz}$ oscillating components of the power is achieved with the improved versions of the control. In this case, also a reduction of the current distortion and unbalance are visible in Figures $12 \mathrm{~b}$ and $12 \mathrm{c}$ in respect to Figure 12a. For instance, the current unbalances, calculated as the ratio between the amplitudes of the negative sequence and of the positive sequence of the currents injected into the grid, are: $9,6 \%$ for the basic control and about 3,2\% for both the improved versions.

\section{Conclusions}

The paper presents four different control schemes of Voltage Source Inverters for applications in distribution network connected Permanent Magnet Wind Generators. A typical dq-axes current control is firstly presented. Then, two modified control schemes in the dq frame are described. They take into account possible negative sequence components of voltages and currents, in order to reduce the $100 \mathrm{~Hz}$ oscillating power injected into the network during grid voltage unbalances. A fourth control approach in the $\alpha \beta$ frame is also described. This approach gives some benefits in terms of computational complexity to respect to the "classical" dq-control.

An ATPDraw model of a $2 \mathrm{MW}$ permanent magnet wind generator with its power electronics parts has been implemented. The model was used for testing in simulations the performances of the two control strategies with negative sequences compensation during network voltage unbalances and voltage dips.

From the simulations, it emerges that the compensation of negative sequence components offers significant benefits in terms of reduction of power oscillations and current unbalance and distortion. Simulation results also put into evidence that the performances of the two modified controls in terms of oscillations reduction are almost equivalent.

\section{Acknowledgement}

This work has been financed by the Research Fund for the Italian Electrical System under the Contract Agreement between RSE (formerly known as ERSE) and the Ministry of Economic Development - General Directorate for Nuclear Energy, Renewable Energy and Energy Efficiency stipulated on July 29, 2009 in compliance with the Decree of March 19, 2009.

\section{References}

[1] O.B.K. Hasnaoui, J. Belhadj, M. Elleuch, "Direct drive permanent magnet synchronous generator wind turbine investigation", in Journal of electrical systems, Vol. 4, Issue 3, September 2008, pp. 1-13.

[2] J. Kearney, M.F. Conlon, E. Coyle, "Analysis of converter connected synchronous wind turbines to grid disturbances", in Proc. of the 46th International Universities' Power Engineering Conference, UPEC2011, Vol. 1, pp. 1-6.

[3] R. Chiumeo, C. Gandolfi, "A three phase photovoltaic power system connected to the MV network: behaviour during voltage dips", in Proc. of the International Conference on Renewable Energies and Power Quality (ICREPQ'11), Las Palmas de Gran Canaria 13-15 April, 2011, pp. 1-6.

[4] M. Örs, "Maximum power point tracking for small scale wind turbines with self excited induction generator", in Journal of Control Engineering and Applied Informatics, Vol. 11, Issue 2, Year 2009, pp. 30-34.

[5] J. Liang, B. Whitby, "Field oriented control of a permanent magnet synchronous generator for use in a variable speed tidal steam turbine", in Proc. of the 46th International Universities' Power Engineering Conference, UPEC2011, Vol. 1, pp. 1-6.

[6] P. Mattavelli, S. Fasolo, "A closed-loop selective harmonic compensation for active filters", in Proc. of the Fifteenth Annual IEEE Applied Power Electronics Conference and Exposition, APEC 2000, Vol 1, pp. 399-405.

[7] A. Ortiz, M. Aredes, L.G.B. Rolim, E. Bueno, P. Rodriguez, "A new current control for the STATCOM based on secondary order generalized integrators", in Proc. of the IEEE Power Electronics Specialists Conference, PESC 2008, 15-19 June 2008, Rhodes, pp. 1-6.

[8] D.N. Zmood, D.G. Holmes, "Stationary frame current regulation of PWM inverters with zero steady state errors", in Proc. of the IEEE Power Electronics Specialists Conference, PESC '99, Charleston, South Carolina, pp. 1185-1190. 